\title{
Chalcogenide glass-ceramic with self-organized heterojunctions: application to photovoltaic solar cells
}

\author{
Xianghua Zhang ${ }^{1}$, Ilia Korolkov ${ }^{1}$, Bo Fan ${ }^{1}$, Michel Cathelinaud ${ }^{1, *}$, Hongli Ma ${ }^{1}$, Jean-Luc Adam ${ }^{1}$, \\ Odile Merdrignac ${ }^{1}$, Laurent Calvez ${ }^{1}$, Hervé Lhermite ${ }^{2}$, Laurent Le Brizoual ${ }^{2}$, Marcel Pasquinelli ${ }^{3}$, \\ and Jean-Jacques Simon ${ }^{3}$ \\ ${ }^{1}$ Univ. Rennes, CNRS, ISCR -UMR6226, 35000 Rennes, France \\ ${ }^{2}$ Univ. Rennes, CNRS, IETR -UMR6164, 35000 Rennes, France \\ 3 Aix Marseille Université, CNRS, Université de Toulon, IM2NP UMR 7334, 13397 Marseille, France
}

Received: 31 January 2017 / Received in final form: 25 September 2017 / Accepted: 10 January 2018

\begin{abstract}
In this work, we present for the first time the concept of chalcogenide glass-ceramic for photovoltaic applications with the $\mathrm{GeSe}_{2}-\mathrm{Sb}_{2} \mathrm{Se}_{3}-\mathrm{CuI}$ system. It has been demonstrated that thin films, deposited with the sputtering technique, are amorphous and can be crystallized with appropriate heat treatment. The thin film glassceramic behaves as a p-type semiconductor, even if it contains p-type $\mathrm{Cu}_{2} \mathrm{GeSe}_{3}$ and n-type $\mathrm{Sb}_{2} \mathrm{Se}_{3}$. The conductivity of $\mathrm{Sb}_{2} \mathrm{Se}_{3}$ has been greatly improved by appropriate iodine doping. The first photovoltaic solar cells based on the association of iodine-doped $\mathrm{Sb}_{2} \mathrm{Se}_{3}$ and the glass-ceramic thin films give a short-circuit current density $\mathrm{J}_{\mathrm{SC}}$ of $10 \mathrm{~mA} / \mathrm{cm}^{2}$ and an open-circuit voltage $\mathrm{V}_{\mathrm{OC}}$ of $255 \mathrm{mV}$, with a power conversion efficiency of about $0.9 \%$.
\end{abstract}

Keywords: chalcogenide / glass-ceramics / photovoltaic solar cells / heterojunction

\section{Introduction}

Glass-ceramics are composite materials containing a mixture of amorphous and crystalline phases. They have been mainly developed for improving the thermomechanical properties of glasses [1-3]. A wide range of products is now commercially available from mirrors for large telescopes to cooking plates. More recently, glass-ceramics have also been intensively studied as highly efficient luminescent materials in order to simultaneously benefit from the advantages of glasses (easy production and shaping) and of crystals (favorable environment of the luminescence of active ions) [4,5].

Chalcogenide glasses are glasses based on chalcogen elements (S, Se and Te) associated with other elements such as Ge, Sb. They are particularly studied for their good transparence in the mid infrared region [6-9]. Glassceramics are generally obtained by controlling the crystallization of the precursor glass through heat treatment. This thermal process is critical for generating appropriate crystalline phases which will determine the properties of the final composite material.

Our study on the glass forming system $\mathrm{GeSe}_{2}-\mathrm{Sb}_{2} \mathrm{Se}_{3}$ $\mathrm{CuI}$ was motivated by the development of infrared transmission glass-ceramics [10]. Controlled crystallization

\footnotetext{
* e-mail: michel.cathelinaud@univ-rennes1.fr
}

of selected glasses leads to glass-ceramics containing simultaneously p-type $\mathrm{Cu}_{2} \mathrm{GeSe}_{3}$ (bandgap around $0.8 \mathrm{eV}$ ) and n-type $\mathrm{Sb}_{2} \mathrm{Se}_{3}$ (bandgap between 1.1 and $1.3 \mathrm{eV}$ ) semiconducting phases with appropriate bandgap for solar energy harvesting [11].

The high-resolution transmission electron microscope (HRTEM) indicates, in addition, that these two phases are generally assembled, forming therefore a high number of p-n junctions at a nanoscale and leading to some quite exceptional photoelectric properties such as extremely long lifetime of minority charge carriers in the range of $14 \mu \mathrm{s}$.

Previous studies, mentioned above, have led to an optimized composition of $40 \mathrm{GeSe}_{2}-40 \mathrm{Sb}_{2} \mathrm{Se}_{3}-20 \mathrm{CuI}$ (in molar percentage) with the highest photocurrent. In this work, we have decided to use this composition to demonstrate the feasibility of a new type of thin film photovoltaic solar cells by using this glass-ceramic. To the best of our knowledge, this is the first time that a glassceramic is proposed for a photovoltaic application.

\section{Experimental section}

\subsection{Glass-ceramic target}

For the synthesis of chalcogenide glass-ceramics, it is essential to operate in vacuum because of the relatively high vapor pressure of chalcogenide melt and their tendency to react with oxygen, especially at high temper- 


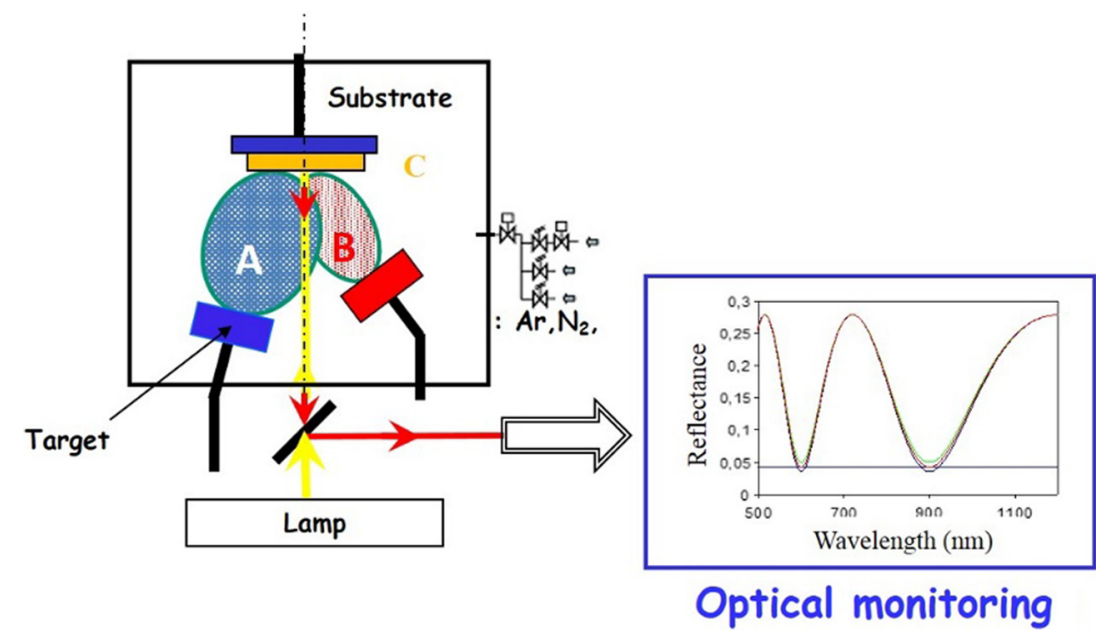

Fig. 1. Schematic illustration of the deposition system where target A is the glass-ceramic GC40-40-20 and target B is $\mathrm{Sb}_{2} \mathrm{Se}_{3}: \mathrm{I}_{\text {. The }}$ set-up is equipped with an optical monitoring system by measuring the reflectance on substrate C, where the film is deposited. The distance between target and substrate is to $55 \mathrm{~mm}$.

atures. Consequently, the glass-ceramic targets have been produced by using the melt-quenching process with the corresponding element mixtures in sealed silica tube under vacuum. This technique is commonly used for chalcogenide glass preparation and has been described in detail elsewhere [6].

The $40 \mathrm{GeSe}_{2}-40 \mathrm{Sb}_{2} \mathrm{Se}_{3}-20 \mathrm{CuI}$ target (GC40-40-20) and the iodine-doped $\mathrm{Sb}_{2} \mathrm{Se}_{3}$ targets were prepared using polycrystalline germanium (99.999\% Umicore), antimony (99.999\% Umicore), selenium (99.999\% Umicore), CuI (98\% Aldrich) and iodine (99.9\% Aldrich) as starting materials which are weighed according to the composition in order to get a sample of about $60 \mathrm{~g}$. The preparation was done in a silica ampoule with $50 \mathrm{~mm}$ internal diameter. The tube was cleaned by hydrofluoric acid for about $10 \mathrm{~s}$ to eliminate possible dust, which can be present on the wall of the silica ampoule. It was then thoroughly rinsed with deionized water and dried under vacuum. A vacuum trap placed in liquid nitrogen is used to condense any volatile products and also to improve the vacuum. All the starting materials were loaded into the silica tube which was then sealed under a typical vacuum of around $10^{-5} \mathrm{mbar}$. The tube containing the mixture was put into a rocking furnace and heated to $800^{\circ} \mathrm{C}$ at the rate of $1.5^{\circ} \mathrm{C} / \mathrm{min}$ and hold for about $12 \mathrm{~h}$ to ensure a thorough reaction and homogenization. Then the furnace was cooled down to $700{ }^{\circ} \mathrm{C}$ and the thermal quenching was performed by putting the sealed tube into water at room temperature. The rapid quenching is necessary to avoid excessive crystal growth. The thermal shock in the quenching process generated high mechanical stresses in the glass-ceramics. In order to reduce these stresses, the targets were annealed at $200^{\circ} \mathrm{C}$ for $3 \mathrm{~h}$. The targets were then cooled down slowly and released from the silica ampoule. After the annealing, the two targets: the glass-ceramic GC40-40-20 and the $\mathrm{Sb}_{2} \mathrm{Se}_{3}: \mathrm{I}$ (10 at.\% of iodine named $\left.\mathrm{Sb}_{2} \mathrm{Se}_{3}: \mathrm{I} 10\right)$ with diameter of $50 \mathrm{~mm}$ were obtained with a thickness approximatively of $4 \mathrm{~mm}$. They will be used as sputtering targets.

\subsection{Thin film deposition}

The sputtering technique is a widely used thin film deposition method with good composition transfer from the target to the substrates, even in case of complex composition. We use radio-frequency sputtering technique to deposit thin film and the equipment is a MP600S from Plassys. To control the thin film growth in real time, the deposition facility is equipped with an online optical monitoring system by reflection [12-14]. This system is particularly useful for controlling the crystallization of the thin films. The first step of the thin film deposition is to obtain a homogenous amorphous film and therefore, a relatively low deposition pressure of $5 \times 10^{-3} \mathrm{mbar}$ to ensure a high compactness [15]. The deposition chamber was pumped to a residual pressure of less than $2 \times 10^{-7}$ mbar before each deposition. All targets are etched by argon plasma during about $5 \mathrm{~min}$ to eliminate surface contamination. The RF sputtering powers are fixed to $13 \mathrm{~W}$ on a $50 \mathrm{~mm}$ diameter target and the obtained DC bias is typically between 83 and 95 volts. The deposition rate is respectively about $4 \mathrm{~nm} / \mathrm{min}$ and $6 \mathrm{~nm} / \mathrm{min}$ for GC404020 and $\mathrm{Sb}_{2} \mathrm{Se}_{3}: \mathrm{I}$.

The deposition system is schematically illustrated in Figure 1, with the possibility of using three confocal targets of $50 \mathrm{~mm}$ in diameter (only two targets are illustrated for the sake of clarity). The $40 \mathrm{GeSe}_{2}-40 \mathrm{Sb}_{2} \mathrm{Se}_{3}-20 \mathrm{CuI}$ precursor glass and the iodine-doped $\mathrm{Sb}_{2} \mathrm{Se}_{3}$ targets were prepared by using the melt-quenching technique discussed above. These two targets are used for the deposition of multilayer structures, necessary for the photovoltaic device.

A thermal annealing system is installed to heat the backside of the substrates, during or after the deposition of thin films. Commercial ITO (Indium-Tin Oxide of $30 \Omega / \mathrm{sq}$ ) coated soda lime glass ( $1 \mathrm{~mm}$ of thickness) has been used in this work. Two gold contacts $(2 \mathrm{~mm}$ diameter) were deposited through a physical mask at the end with a LEICA DC Sputtering system. 


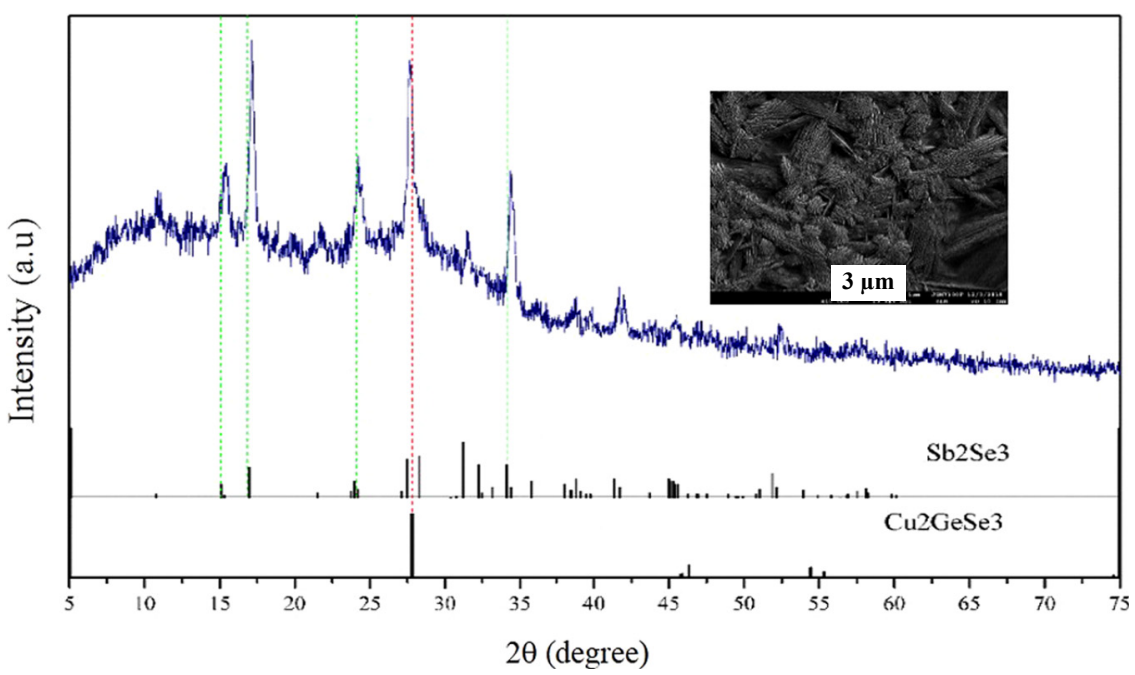

Fig. 2. The X-ray diffraction pattern and the morphology of crystallized $40 \mathrm{GeSe}_{2}-40 \mathrm{Sb}_{2} \mathrm{Se}_{3}-20 \mathrm{CuI}$ thin film. The diffraction peaks can be assigned to the orthorhombic phases for $\mathrm{Sb}_{2} \mathrm{Se}_{3}$ (JCPDS 75-1462) and $\mathrm{Cu}_{2} \mathrm{GeSe}_{3}$ (JCPDS 85-1699).

\subsection{Heat treatment of thin films}

The heat treatment is a critical step to be optimized for obtaining appropriate microstructure of the thin films. It can be done, in-situ, during or after the deposition of the films by heating the substrate and the crystallization and cooling were monitored by measuring the optical reflectance. The pressure during the heat-treatment is low to avoid any contamination. The temperature for the heattreatment is optimized and the best temperature is $400{ }^{\circ} \mathrm{C}$ for the GC40-40-20. The first criterion to stop heat treatment is based on a fast decrease of the reflectance at $790 \mathrm{~nm}$ (wavelength used for monitoring), with more than $10 \%$ of variation. The second criterion is to observe a stability of reflectance when the temperature decreases during the cooling. When these two criteria are satisfied, the annealing will be stopped. The duration of the heat treatment is typically between 5 and $60 \mathrm{~min}$ for different thin films, which crystallize more or less easily. This duration is optimized for each thin film.

\subsection{Characterization and measurements}

X-ray diffraction (XRD) was carried out on a PANalytical's X-ray diffractometer with a step width of $0.02^{\circ}$ and a counting duration of $0.13 \mathrm{~s} / \mathrm{step}$. The structure of the GC40-40-20 and $\mathrm{Sb}_{2} \mathrm{Se}_{3}$ :I films was investigated by XRD with $\mathrm{Cu} \mathrm{K} \alpha 1$ and $\mathrm{Cu} \mathrm{K \alpha 2}$ (wavelengths of $0.154060 \mathrm{~nm}$ and $0.154443 \mathrm{~nm}$ respectively). Scanning electron microscope (SEM) images and energy dispersive spectrometer (EDS) elemental mappings were obtained with a JEOL JSM$7100 \mathrm{~F}$.

Optical reflectance was measured by using a Perkin Elmer lambda 900 spectrophotometer.

The photovoltaic devices were characterized under an AM1.5G solar simulator with an illumination intensity of $100 \mathrm{~mW} / \mathrm{cm}^{2}$ ( $450 \mathrm{~W}$ Oriel, model 9119). The Keithley 2400 was used to measure the current-voltage characteristics. The acquisition scan rate was $0.05 \mathrm{~V} / \mathrm{s}$. The device area ( $2 \mathrm{~mm}$ in diameter) was defined by the size of the gold electrodes. During the measurements, a diaphragm of $2 \mathrm{~mm}$ in diameter was placed in front of the plot of gold to illuminate only this plot. No temperature control was applied.

A HMS-5000 Hall effect measurement system (Ecopia) was used to measure the concentration and the mobility of the minority charge carriers, the resistivity, the conductivity and the Hall coefficient at room temperature for thin films.

Photo-electro-chemical (PEC) measurements have been performed by using the classic 3-electrode method. The sample to be measured was used as the working electrode in association with a platinum counter electrode and the $\mathrm{Ag} / \mathrm{AgCl}$ reference electrode. Aqueous solution of $0.5 \mathrm{M} \mathrm{LiClO}_{4}$ was used as electrolyte. The potential difference was measured between the reference electrode and the working electrode. The current density was measured between the $\mathrm{Pt}$ electrode and the working electrode. A potentiostat AUTOLAB METROHM and a chopped white light lamp of $150 \mathrm{~W}$ with an intensity of $30 \mathrm{~mW} / \mathrm{cm}^{2}$ on the sample were employed to record current-voltage (I-V) characteristics. The result was analyzed by using the NOVA software.

\section{Results and discussion}

Thin films deposited with the substrate at room temperature, are confirmed, by XRD, to be amorphous. The asdeposited thin films, without annealing, have high electric resistance and no photocurrent can be detected. Optical monitoring indicates that the heat treatment of the precursor amorphous thin films is efficient at temperatures higher than $300^{\circ} \mathrm{C}$ in order to get crystallized thin film of GC404020. The XRD pattern, shown in Figure 2, confirms the presence of the two crystalline phases, $\mathrm{Cu}_{2} \mathrm{GeSe}_{3}$ and $\mathrm{Sb}_{2} \mathrm{Se}_{3}$, and an amorphous phase like in the bulk glassceramic samples. As discussed before, antimony selenide 


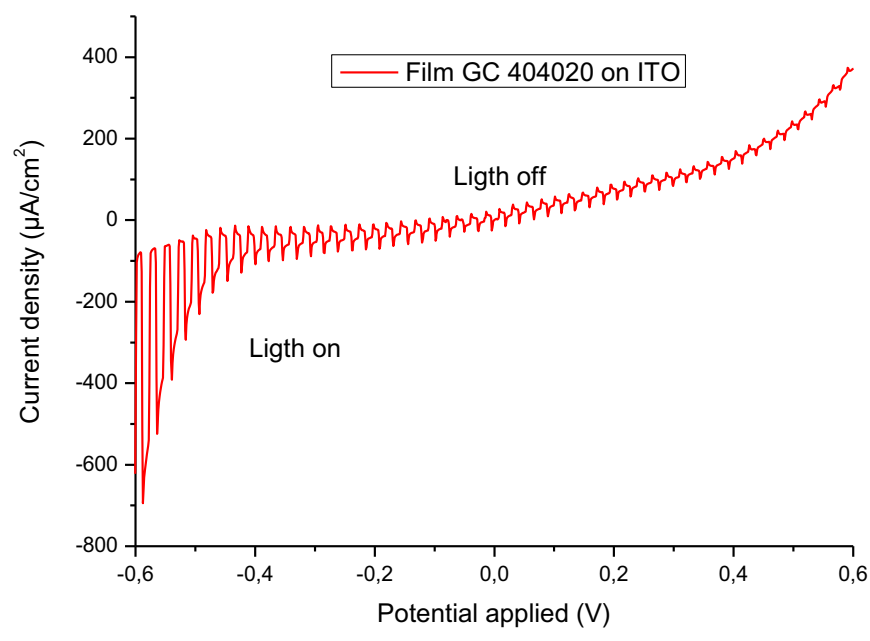

Fig. 3. Photo-electro-chemical measurement showing the dark and light current-voltage characteristics of GC 404020 thin film, indicating clearly it is a p-type semi-conductor.

$\left(\mathrm{Sb}_{2} \mathrm{Se}_{3}\right)$ has an orthorhombic structure with an optical band gap of $1.1-1.3 \mathrm{eV}$ [16]. The copper germanium selenide $\left(\mathrm{Cu}_{2} \mathrm{Ge}_{2} \mathrm{Se}_{3}\right)$ has an optical bandgap of $0.8 \mathrm{eV} \mathrm{[17].}$ The morphology of the film is also shown in the same figure and the needle-like structure of $\mathrm{Sb}_{2} \mathrm{Se}_{3}$ can be clearly seen.

The PEC measurement (Fig. 3) shown clearly important photocurrent at negative bias, indicating that the crystallized GC40-40-20 thin film is a p-type semiconductor. There is an important difference with the bulk glassceramic showing a simultaneous p-type and n-type semiconducting behavior [11]. In fact, in the above mentioned previous study, it has been demonstrated that, in the bulk glass-ceramics, the p-type semiconducting phase is $\mathrm{Cu}_{2} \mathrm{GeSe}_{3}$ and the n-type is iodine doped $\mathrm{Sb}_{2} \mathrm{Se}_{3}$. $\mathrm{Sb}_{2} \mathrm{Se}_{3}$ is a semiconductor with very low conductivity. The iodine doping is essential for improving the conductivity of $\mathrm{Sb}_{2} \mathrm{Se}_{3}$, as shown in Figure 4. However, due to its relatively high partial pressure, iodine content will be lower in the thin film than in the bulk target. This explains well the different behaviors between bulk and thin film in terms of PEC results.

As the thin film glass-ceramic $40 \mathrm{GeSe}_{2}-40 \mathrm{Sb}_{2} \mathrm{Se}_{3}-$ $20 \mathrm{CuI}$ is only p-type semiconductor, a n-type semiconductor is necessary to create $\mathrm{p}$-n junctions. It has been demonstrated, by Hall effect measurements and PEC measurements, that iodine-doped $\mathrm{Sb}_{2} \mathrm{Se}_{3}$ was a n-type semiconductor with appropriate conductivity. Therefore, $\mathrm{Sb}_{2} \mathrm{Se}_{3}$ :I thin films have been developed with a iodinedoping level of $10 \mathrm{~mol} \%$.

For the $\mathrm{Sb}_{2} \mathrm{Se}_{3}: \mathrm{I}$ film, the heat treatment temperature should be lower to avoid decomposition of this film and to limit the loss of iodine. As an example, a heat treatment at $272{ }^{\circ} \mathrm{C}$ with a pressure of $0.25 \mathrm{mbar}$ leads to the crystallization of $\mathrm{Sb}_{2} \mathrm{Se}_{3}$ without any impurity phase, as shown in Figure 5. The introduction of iodine in $\mathrm{Sb}_{2} \mathrm{Se}_{3}$, evidenced by the important increase of conductivity, does not lead to a significant shift of the diffraction peaks. This can be attributed to the close radii of $\mathrm{Se}^{2-}$ and $\mathrm{I}^{-}$ions (respectively $1.98 \AA$ and $2.16 \AA$ ). Iodine doped $\mathrm{Sb}_{2} \mathrm{Se}_{3}$ is a ntype semiconductor with a resistivity in the range of

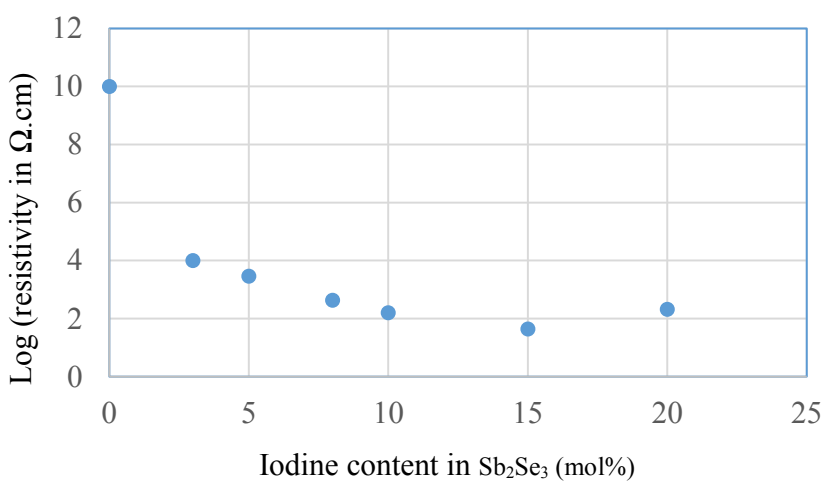

Fig. 4. Resistivity as function of iodine doping in $\mathrm{Sb}_{2} \mathrm{Se}_{3}$.

$100 \Omega \cdot \mathrm{cm}$ for heat treatment conditions inferior to $272^{\circ} \mathrm{C}$. Above this temperature, the films deposited on glass (Bk7 or soda-lime glass) tend to decompose and result in a bad mechanical adhesion on substrate. EDS measurements indicate some losses of selenium and iodine during the thin film deposition. Optimized heat treatment does induce noticeable composition change.

In view of a different annealing temperatures, the GC40-40-20 film should be deposited before the $\mathrm{Sb}_{2} \mathrm{Se}_{3}: \mathrm{I}$ film during the preparation of the solar cells.

The controlled crystallization has a key impact on the performance of these different materials. The heat treatment is generally realized inside the vacuum chamber after the deposition of each layer by heating the backside of the substrate. It has been observed that a relatively thick film will lead to inhomogeneous crystallization. For this reason, we decided to design a PV device with relatively thin films. The structure of the photovoltaic device is shown in Figure 6. The choice of the first layer deposited on ITO film has been fixed in respect with the band gap of thin films and the heat treatment conditions. The selected thickness is $220 \mathrm{~nm}$ for the layer of $\mathrm{Sb}_{2} \mathrm{Se}_{3}: \mathrm{I}$ and $150 \mathrm{~nm}$ for the GC40-40-20 glass-ceramic layer. These thin films are heat treated together after the deposition during $40 \mathrm{~min}$ at $270^{\circ} \mathrm{C}$.

Figure 6 gives also the current-voltage characteristics in dark and under illumination of a solar simulator. This device gives a short-circuit current density $\mathrm{J}_{\mathrm{SC}}$ of $10 \mathrm{~mA} / \mathrm{cm}^{2}$ and an open-circuit voltage $\mathrm{V}_{\mathrm{OC}}$ of $255 \mathrm{mV}$. The illumination does not lead to a perfect offset of the I-V curves. The fill factor is $35 \%$, leading to a power conversion efficiency of about $0.9 \%$.

In order to verify the origin of the photovoltaic effect, two separate junctions, $\mathrm{Au} / \mathrm{Sb}_{2} \mathrm{Se}_{3}: \mathrm{I}$ and chalcogenide glass-ceramics/ITO have been fabricated. The I-V characteristic of these two junctions has been measured, indicating clearly two ohmic contacts. Similar results have been obtained with $\mathrm{Au} / \mathrm{Sb}_{2} \mathrm{Se}_{3}$ junction by another group [18]. Therefore, we can conclude that the photovoltaic effect is induced by the junction chalcogenide glassceramic $/ \mathrm{Sb}_{2} \mathrm{Se}_{3}$ :I.

The reproducibility of this device has been tested with similar results: The short-circuit current density is typically in the range of $9-10 \mathrm{~mA} / \mathrm{cm}^{2}$ and more variation for the $\mathrm{V}_{\mathrm{OC}}$ has been observed in the range of $230-280 \mathrm{mV}$. 


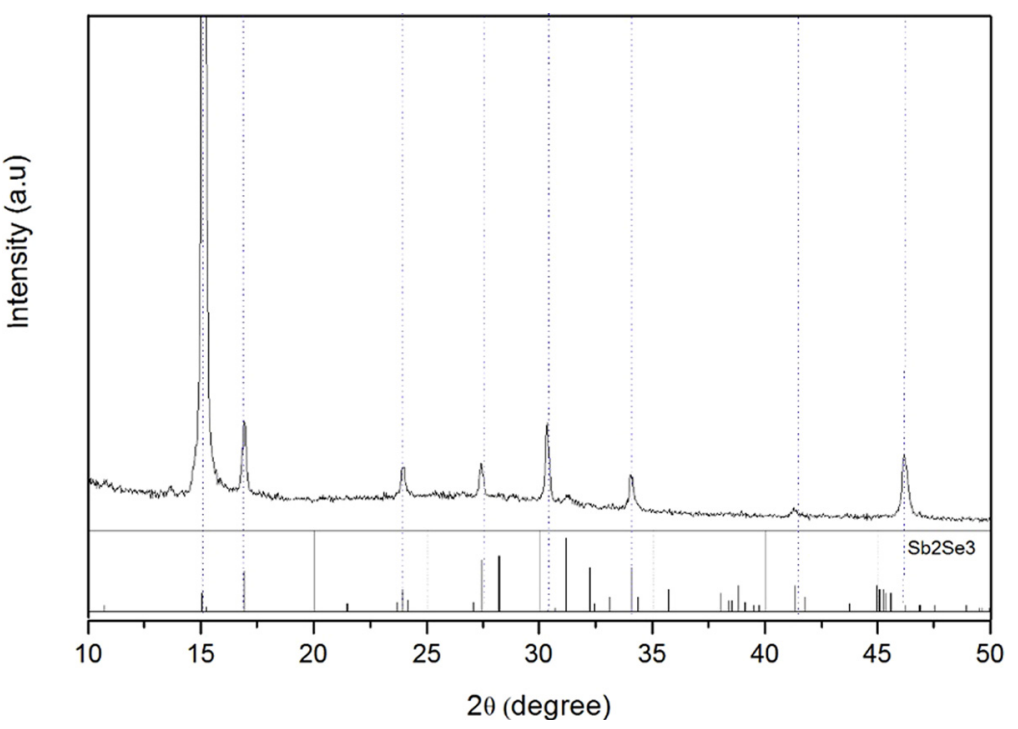

Fig. 5. XRD pattern of $\mathrm{Sb}_{2} \mathrm{Se}_{3}$ :I film on BK7 after heat treatment at $272^{\circ} \mathrm{C}$. The diffraction peaks can be assigned to the orthorhombic phases for $\mathrm{Sb}_{2} \mathrm{Se}_{3}$ (JCPDS 75-1462).
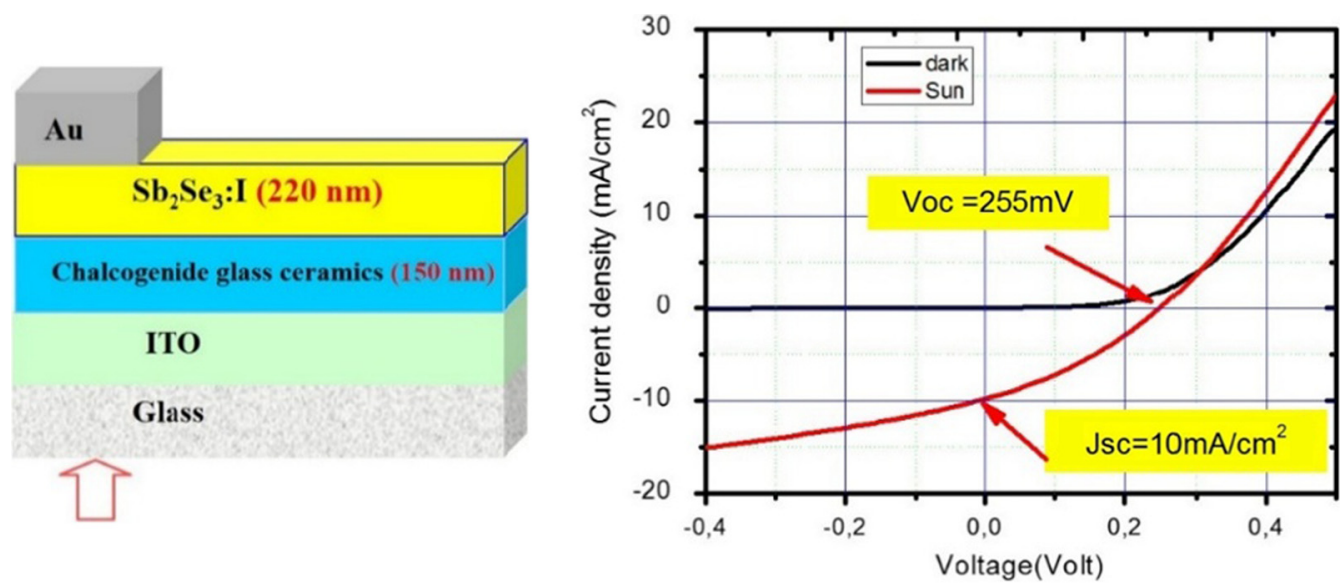

Fig. 6. The schematized structure and the I-V characteristics of the photovoltaic device using chalcogenide glass-ceramics.

\section{Conclusion and perspectives}

In this work, we have demonstrated the feasibility of $\mathrm{GeSe}_{2}-\mathrm{Sb}_{2} \mathrm{Se}_{3}-\mathrm{CuI}$ thin film with controlled crystallization by using the sputtering technique. The XRD has confirmed the co-existence of $\mathrm{Cu}_{2} \mathrm{GeSe}_{3}$ with the $\mathrm{Sb}_{2} \mathrm{Se}_{3}$ in the partially crystallized thin film as in the previously studied bulk glass-ceramics. The thin film shows only a p-type semiconductor behaviors, while the bulk glass-ceramics show simultaneous p-type and n-type characteristics. Therefore, a n-type semiconductor has been developed by doping $\mathrm{Sb}_{2} \mathrm{Se}_{3}$ with iodine, leading to considerably decreased resistivity of $\mathrm{Sb}_{2} \mathrm{Se}_{3}$.

Photovoltaic devices have been fabricated based on the chalcogenide glass-ceramics associated with the iodinedoped $\mathrm{Sb}_{2} \mathrm{Se}_{3}$ which is a n-type semiconductor. For this totally new type of solar cells, an interesting Jsc of $10 \mathrm{~mA} / \mathrm{cm}^{2}$ before any optimization has been reproducibly obtained with a very thin absorber layer. The power conversion efficiency is about $1 \%$. The structure and the absorber's thickness should be optimized in order to increase the power conversion efficiency of this photovoltaic device using totally new materials.

\section{References}

1. G. Partridge, Glass Technol. 35, 116 (1994)

2. D.S. Baik, K.S. No, J.S.S. Chun, J. Am. Ceram. Soc. 78, 1217 (1995)

3. H.L. Ma, X.H. Zhang, J. Lucas, J. Non-Cryst. Solids 317, 270 (2003)

4. M. Takahashi, M. Izuki, R. Kanno, Y. Kawamoto, J. Appl. Phys. 83, 3920 (1998)

5. Q. Luo, X.S. Qiao, X.P. Fan, H.Y. Fu, J.L. Huang, Y.J. Zhang, B. Fan, X.H. Zhang, J. Am. Ceram. Soc. 95, 1042 (2012)

6. C.D. Hwan, K.H. Jeong, H. Yeon et al., Appl. Opt. 51, 5649 (2012) 
7. Chalcogenide glasses, preparation, properties and applications, edited by J.L. Adam, X. Zhang (Woodhead Publishing, 2013)

8. A. Yang, M. Zhang, L. Li et al., J. Am. Ceram. Soc. 99, 12 (2016)

9. X.H. Zhang, Y. Guimond, Y. Bellec, J. Non-Cryst. Solids 326 \& 327, 519 (2003)

10. L. Calvez, H.L. Ma, J. Lucas, X.H. Zhang, Phys. Chem. Glasses - Eur. J. Glass Sci Technol. B 47, 142 (2006)

11. X.H. Zhang, Y. Xu, Q. Shen, B. Fan, X. Qiao, X. Fan, H. Yang, Q. Luo, L. Calvez, H.L. Ma, M. Cathelinaud, J.J. Simon, J. Mater. Chem. A 2, 17099 (2014)

12. B. Badoil, F. Lemarchand, M. Cathelinaud, M. Lequime, Opt. Express 16, 12008 (2008)
13. W. Shen, M. Cathelinaud, M. Lequime, F. Charpentier, V. Nazabal, Opt. Express 16, 373 (2008)

14. V. Nazabal, M. Cathelinaud, W. Shen, P. Nemec, F. Charpentier, H. Lhermite, M.L. Anne, J. Capoulade, F. Grasset, A. Moreac, S. Inoue, M. Frumar, J.L. Adam, M. Lequime, C. Amra, Appl. Opt. 47, C114 (2008)

15. J.A. Thornton, J Vac. Sci. Technol. A 4, 3059 (1986)

16. G.H. Liang, Z.H. Zheng, P. Fan, J.T. Luo, J.G. Hu, X.H. Zhang, H.L. Ma, B. Fan, Z.K. Luo, D.P. Zhang, Sol Energy Mater. Sol. Cells 174, 263 (2018)

17. B.K. Sarkar, A.S. Verma, P.S. Deviprasad, Physica B 406, 2847 (2011)

18. C. Chen, D.C. Bobela, Y. Yang, S.C. Lu, K. Zeng, C. Ge, B. Yang, L. Gao, Y. Zhao, M.C. Beard, J. Tang, Front Optoelectron. 10, 18 (2017)

Cite this article as: Xianghua Zhang, Ilia Korolkov, Bo Fan, Michel Cathelinaud, Hongli Ma, Jean-Luc Adam, Odile Merdrignac, Laurent Calvez, Hervé Lhermite, Laurent Le Brizoual, Marcel Pasquinelli, Jean-Jacques Simon, Chalcogenide glass-ceramic with self-organized heterojunctions: application to photovoltaic solar cells, EPJ Photovoltaics 9, 3 (2018) 